\title{
Inter-Association Consensus Statement on Best Practices for Sports Medicine Management for Secondary Schools and Colleges
}

\author{
Ron Courson, ATC, PT, NREMT-I, CSCS (Co-Chair)*; Michael Goldenberg, MS, \\ ATC (Co-Chair) ${ }^{\star} \dagger ;$ Kevin G. Adams, CAAł; Scott A. Anderson, ATC§; \\ Bob Colgatell; Larry Cooper, MS, LAT, ATC*; Lori Dewald, EdD, ATC, MCHES, \\ F-AAHEף; R.T. Floyd, EdD, ATC*; Douglas B. Gregory, MD, FAAP\#; Peter A. \\ Indelicato, MD**; David Klossner, PhD, ATC††; Rick O'Leary, MS, ATC, AT/L*;

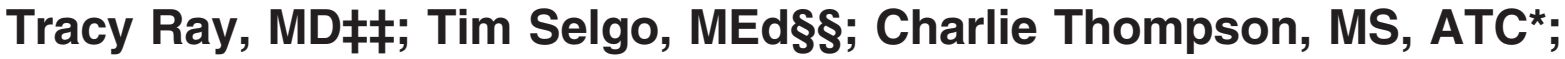 \\ Gary Turbak, DHSc, ATCIIII
}

*National Athletic Trainers’ Association; †The Lawrenceville School; ¥National Interscholastic Athletic Administrators Association; §College Athletic Trainers' Society; IINational Federation of State High School Associations; ПAmerican College Health Association; \#American Academy of Pediatrics; **American Orthopaedic Society for Sports Medicine;

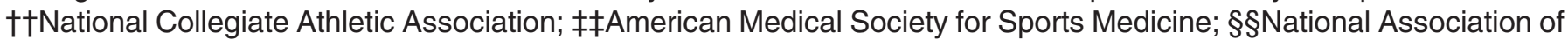
Collegiate Directors of Athletics; IIIINational Association of Intercollegiate Athletics

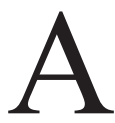

lthough significant advances have occurred within athletic training and sports medicine in the last few decades, the fields can be traced back to the ancient Greek civilization and the establishment of the Olympic Games. ${ }^{1}$ Today, more than 900 different sports are practiced worldwide; however, not all of them have a physical component. ${ }^{2}$ In the United States alone, more than 7.6 million students participate in organized secondary school athletics, whereas in 2012, more than 420000 student-athletes represented their colleges in athletic play. ${ }^{3,4}$ Athletics are part of the educational process for many students and add to the growth of the adolescent and young adult. Secondary school students involved in athletics with proper coaching demonstrate better academic achievement, miss less school, and learn lifelong lessons for success. ${ }^{5}$

It is estimated that more than 1.4 million injuries occur yearly to athletes playing 9 sports at the secondary school level and approximately 209000 yearly at the collegiate level across 25 National Collegiate Athletic Association sports (Datalys Center for Sports Injury Research and Prevention, written communication, April 15, 2013). ${ }^{6}$ These statistics take into account injuries that occur in both practice and game situations. In addition, an unknown number of injuries occur in nonscholastic sports, primarily as a result of overuse, either alone or resulting from the cumulative effects of nonscholastic and scholastic sports participation. As concerns grow over the number of musculoskeletal injuries, as well as life-threatening conditions and traumatic brain injuries such as concussions, more secondary schools and colleges are being forced to reevaluate the medical services they provide their athletes.
Athletes at secondary schools with proper medical teams that include an athletic trainer sustain a lower incidence of injuries (both acute and recurring) than athletes at schools without athletic trainers. Athletes at secondary schools with athletic trainers incur more diagnosed concussions, demonstrating better identification of these injuries. ${ }^{7}$ According to the American Medical Association, ${ }^{8}$ "[T] medicine unit should be composed of an allopathic or osteopathic physician director with unlimited license to practice medicine, an athletic health coordinator (preferably an athletic trainer certified by the Board of Certification, Inc $[\mathrm{BOC}])$, and other necessary personnel." This document on best practice in sports medicine management brings together resources and views from 11 associations that promote the health and well-being of the student-athlete.

Modern athletic training is a young, fast-growing health care profession ${ }^{9}$; thus, many physicians and administrators are still developing proper working relationships with and appropriate expectations for athletic trainers. Wide variations exist in the administration of sports medicine programs, chains of command, and selection and evaluation of the sports medicine team. Further, different athletic training settings (eg, secondary schools, small colleges, large colleges) vary widely in staffing, resources, and budgets.

This consensus paper is written to assist superintendents of schools, secondary school athletic directors, college and university athletic department administrators, athletic trainers, and team and school physicians by presenting the best practices in sports medicine management in the secondary and collegiate settings. This document outlines important considerations regarding (1) duties and respon- 
sibilities of the athletic trainer and team physician; (2) supervisory relationships and the chain of command within the sports medicine team; (3) decision-making authority regarding approval for participation of student-athletes, as well as injury management and return to sport participation status after injury or illness; (4) administrative authority for the selection, renewal, and dismissal of related medical personnel; and (5) performance-appraisal tools for the sports medicine team. To date, these recommendations have been endorsed by the American Academy of Pediatrics, American College Health Association, American Medical Society for Sports Medicine, American Orthopaedic Society for Sports Medicine, College Athletic Trainers' Society, National Association of Collegiate Directors of Athletics, National Association of Intercollegiate Athletics, National Athletic Trainers' Association (NATA), National Federation of State High School Associations, and National Interscholastic Athletic Administrators Association.

\section{Athlete-Centered Medicine}

The term "patient-centered care" refers to the delivery of health care services that are focused on the individual patient's needs and concerns. The same concept, "athletecentered care," applies in sports medicine. ${ }^{10}$ Sports medicine physicians and athletic trainers are often presented with an ethical dilemma when an individual athlete's best medical interests conflict with the performance expectations of authority figures (eg, coaches, parents). In almost every circumstance involving the provision of medical care, the legal responsibility for the decision to allow an injured athlete to return to sports participation ultimately belongs to a licensed physician. ${ }^{11}$ In many situations, a physician who is a sports medicine specialist will authorize an athletic trainer to guide the rate at which an injured athlete is exposed to progressively increasing physical demands, but the physician is still ultimately responsible for the athletic trainer's clinical practice decisions. $^{12}$

The Appendix provides 10 principles to guide institutions and organizations in assessing existing administrative policies, procedures, and professional service relationships. Many of these principles correspond to concepts addressed by the BOC Standards of Professional Practice, ${ }^{13}$ the Code of Ethics of the NATA, ${ }^{14}$ and state medical practice regulations.

\section{Duties and Responsibilities of the Athletic Trainer and Team Physician}

All stakeholders who have as their primary focus the immediate and long-term health and well-being of the individual athlete should be involved in creating the specific institution's job descriptions and expectations for all sports medicine providers. This section outlines duties and responsibilities of the athletic trainer, as well as the team physician, who has ultimate responsibility for the care provided by the sports medicine team.

The athletic trainer's principal responsibility is to provide for the well-being of individual athletes, allowing them to achieve their maximum potential. To accomplish this, athletic trainers work under the direction of the team physician or school medical director and generally are responsible for or actively involved with
- Developing and implementing a comprehensive emergency action plan;

- Preventing, recognizing, diagnosing, referring, treating, and rehabilitating injuries;

- Establishing criteria for safe return to practice and play and implementing the return-to-play process;

- Establishing and operating treatment facilities for both practice and game situations that follow national and local standards;

- Determining which venues and activity settings require the on-site presence of the athletic trainer and team physician and which require that they be available;

- Establishing guidelines for the selection, fit, function, and maintenance of all athletic equipment;

- Maintaining accurate medical records for each athlete;

- Reviewing the design and implementation of strength and conditioning programs for safety and appropriateness related to injury and illness prevention and providing recommendations for change when indicated;

- Establishing a safe practice and playing environment by monitoring environmental risk factors such as meteorologic conditions;

- Communicating with coaches about each injured or ill athlete's condition and progress, in cooperation with the team physician (Health Insurance Portability and Accountability Act [HIPAA] and Family Educational Rights and Privacy Act [FERPA] rules apply); and

- Communicating with parents or guardians and spouses when appropriate about the injured or ill athlete's status, in cooperation with the team physician (HIPAA/FERPA rules apply).

Like all health care providers, the team physician's first obligation is to the well-being of the athletes under the care of the sports medicine team. The physician's judgment should be governed only by medical considerations. The team physician should actively integrate his or her medical expertise with that of other health care providers, including medical specialists, athletic trainers, and allied health professionals. ${ }^{15}$ The team physician must have the ultimate authority for making medical decisions regarding the athlete's safe participation.

The team physician has ultimate responsibility for the following duties ${ }^{15}$ :

- Ensuring proper preparation for safe return to participation after an illness or injury;

- Developing a chain of command, with the team physician at the top;

- Coordinating preparticipation screenings, examinations, and evaluations;

- Managing on-the-field injuries;

- Providing medical management of injury and illness;

- Coordinating rehabilitation and return to participation;

- Integrating his or her medical expertise with that of other health care providers, including medical specialists, athletic trainers, and allied health professionals;

- Providing appropriate education and counseling regarding nutrition, strength and conditioning, ergogenic aids, substance abuse, and other medical issues that could affect the athlete;

- Ensuring proper documentation and medical record keeping; 
- Establishing and defining the relationships among all involved parties;

- Educating athletes, parents or guardians, spouses, administrators, coaches, and other necessary parties of concern regarding the athletes;

- Planning and training for emergencies during competition and practice;

- Addressing equipment and supply concerns;

- Providing appropriate event coverage; and

- Assessing environmental concerns and playing conditions.

\section{Supervisory Relationships and Chain of Command Within the Sports Medicine Team}

A variety of models exist for sports medicine administration. Regardless of the model used, responsibilities should be clearly delineated, particularly in cases where the athletic trainer may have responsibilities other than medical care (eg, administrative and academic). This delineation should also define the supervisory relationships for each area of responsibility so that potential role conflicts are minimized and medical care is not sacrificed. Personnel charged with supervising the athletic trainer's various roles must recognize the roles and responsibilities they share with the athletic trainer. Deliberate attention must be given to avoid providing conflicting directions to the athletic trainer. All involved should realize that quality medical care must supersede other responsibilities in times of conflict. Clear delineation of responsibilities and supervisory roles should be documented in advance of employment and shared routinely as part of the hiring and selection process, with subsequent documentation becoming part of the employment contract. Typical models of supervisory relationships in sports medicine and the advantages and disadvantages of each are outlined in Table 1. Some institutions may use models that vary from or are a combination of those listed. Regardless of the model used, to avoid both perceived and actual conflicts of interest, in no case should there be a supervisory relationship in which members of the sports medicine team report to a coach. The athletic trainer should always report to the team or school physician.

The potential for conflict of interest is omnipresent in sports medicine. When sports medicine team members provide care to athletes but are employees or appointees of the institution, the potential exists for medical decisions to be made that do not reflect the athlete's best interest. Regardless of the level of play, there is immense pressure toward medical clearance so that athletes can participate. However, to protect the athlete's welfare, the institution must establish a clear line of unchallengeable authority for the team physician and athletic trainer. ${ }^{16-18}$

This line of authority affords sports medicine providers freedom from personal and professional bias in their ethical and medicolegal obligations to the athlete's health. ${ }^{19,20}$ The ability to act unencumbered fosters best-interest medical decisions for and by athletes.

Institutional ownership of athletes' health and welfare can be demonstrated by including the athletic trainer or team physician in the senior-level athletic administration. ${ }^{12}$ This may be accomplished irrespective of the individual's appointment, whether through athletics, academics, university health services, or private practice. Freedom in their professional practice is ensured when neither the team physician nor the athletic trainer has a coach as his or her primary supervisor, and no coach has authority over the appointment or employment of sports medicine providers. ${ }^{12,16}$

Shared responsibility for sports safety involves not just the sports medicine providers but the athletic administration, coaches, participants, and all associated with the athletic program. ${ }^{16}$ Medical decisions made in the athletes' best interests ultimately serve the team's best interests and thereby provide for the institution's well-being. The health care provider's primary responsibility is for the health and safety of the student-athlete; however, an additional responsibility is to protect the institution from liability. Shared responsibility means that roles and authorities must be distinct and well defined, so that each party performs duties unique to its discipline.

The team physician as the final authority for medical clearance is well established in the literature and as a medicolegal principle. ${ }^{15,18,21}$ Even when return-to-play decisions are delegated to an athletic trainer by a team physician, the team physician is still ultimately responsible. ${ }^{13,16}$ The institution must affirm, in policy and protocol, that sports medicine providers are empowered to make best-interest decisions regarding the athlete at all times and in all settings, and these decisions are authoritative and not to be ignored. ${ }^{18}$ This organizational principle must be clearly communicated throughout, from the top down, both in policy and in practice.

Communication is essential among the athlete, team physician, athletic trainer, coaches, strength coaches, parents or guardians, spouse, and administration regarding the approval for participation and injury and illness management. Sports medicine providers bound by HIPAA and FERPA must adhere to mandated guidelines. All communications must be legally compliant, accurate, and consistent. Communication policies should outline specific information that will be reported, by whom, to whom, and in what manner.

Athletes bear responsibility to report injury and illness, whether related or unrelated to sport. The athletic trainer informs the team physician, with serial communications as warranted. The athletic trainer communicates the athlete's participation status, including indicated activity limits, to all coaches. Coaches should notify the athletic trainer when they suspect an athlete has suffered an injury, illness, or other adverse condition or is having a performance or conditioning problem.

Return-to-play decisions should be made in an objective and unbiased fashion and not influenced by the emotion of competition. ${ }^{20}$ Participation decisions should be based on the best available evidence balanced with the sports medicine provider's experience and judgment and with specialty medical expertise as warranted.

Using objective criteria, the sports medicine provider determines whether the athlete is allowed to participate based on medical history, clinical evaluation, and symptoms. Progressive return to play with conditioning followed by sport-specific activity, limited practice, and full practice before resuming competition provides an individualized approach that allows each athlete to advance at the appropriate rate given his or her condition and injury severity. ${ }^{22}$ 
The athlete must be an active participant in medical decisions. Parents or guardians and spouse may be involved whether the athlete is a minor or emancipated. ${ }^{20}$ All sports medicine providers must clearly communicate the shortterm and long-term risks associated with continued athletic participation. ${ }^{23}$ Discussion points should include (1) operative and nonoperative treatment options, with outcomes as known, (2) treatment options that may delay return to play but further the athlete's best medical interests, and (3) treatment options that may hasten return to play but are not in the athlete's best medical interests. The information must be in plain and simple language so the athlete can understand any potential adverse consequences, including catastrophic consequences, and make a responsible decision. ${ }^{24}$ Sports medicine providers should assess the athlete's understanding of the provided information and capacity to make the necessary decision and ensure that the athlete has the freedom to choose among the medical alternatives without coercion or manipulation. ${ }^{20}$

Economics must be considered in determining medical clearance for participation. Team physicians and athletic trainers must recognize the value of competitive athletics to the athlete. Value may be measured in money. At all levels, the athlete, his or her family, and interested others may weigh dreams and finances along with the short-term and long-term prognosis differently than the sports medicine provider, even to the point of rejecting the athlete's best medical option. ${ }^{20}$

\section{Decision-Making Authority Regarding Participation of Athletes, Injury Management, and Return-to-Sport Participation After Injury or IIIness in the Secondary School Setting}

Athletic trainers in the secondary school setting work in conjunction with team physicians. The team physician should be actively involved in the athletic health care program across all teams throughout the year. Athletic trainers need to develop a close working relationship with their team physicians so that competent decision making occurs through a collaborative process. Additionally, the relationship must be one of mutual trust and confidence. This relationship facilitates open communication and shared understanding of expectations of both parties. It allows the athletic trainer to truly be an extension of the team physician, operating under standing orders and following written policies and procedures, to provide the best possible care for the athletes. The team physician should be willing to communicate with the athletic trainer at any time and make athlete evaluation and follow-up care a priority.

Students wishing to participate in sports must undergo a comprehensive physical examination. ${ }^{25-29}$ The purpose of this screening is to search for conditions that might predispose an athlete participating in sports to sudden death, catastrophic injury, or significant exacerbation of a preexisting injury or illness without appropriate management or rehabilitation. ${ }^{29}$ Athletic trainers or other school personnel should hold from participation any athlete who has not provided the school with documentation verifying successful completion of the examination.

All athletic trainers should have in place written policies and procedures regarding injury management and return-to- play decision-making criteria. These documents may be developed jointly by the athletic trainer and team physician; the final written document should be approved by the team physician and supported by the school administration. Additionally, all schools should have written emergency action plans that are practiced and followed in the event of serious injury or illness. ${ }^{27,28}$ The policies and procedures should include specific return-to-play protocols for concussions and other injury and illness situations. They should also indicate that the team physician and, by extension, the collaborating athletic trainer have the final and unquestionable authority regarding return-to-play decisions. Although parents and guardians, coaches, and family physicians can prevent an athlete from participating, none of these individuals can overrule the decision of the team physician working with the athletic trainer to withhold the athlete. The athletic trainer's administrative supervisor may be the athletic director, but medical supervision should rest with the team physician. Because the athletic trainer represents the interests of the school, he or she should be supported in medical decisions by the athletic director and other school administrators, provided the athletic trainer follows established policies and procedures.

Athletes should be encouraged to report their injuries rather than hide them. If the athletic trainer believes that an injury or illness warrants removal of the athlete from part or all of the practice or competition, the athletic trainer should have the authority to do so. Communication with the coach, the athlete's parents or guardians, and, in some cases, the athletic director, is advised. However, communicating the injury situation with those individuals should not be misconstrued as seeking their approval to hold the athlete out of competition or practice. Parents or guardians and coaches are not allowed to override the athletic trainer's decision to remove or hold an athlete from participation due to injury or illness.

When athletes seek medical attention outside the school's designated sports medicine providers, it is advisable for the outside provider to contact the athletic trainer. Formal methods of communication (forms) should be developed to facilitate this exchange and describe the expectations of the outside medical provider. Doing so creates a dialogue between the outside provider and the school sports medicine providers and facilitates agreement regarding the rehabilitation process and return-to-play decisions. When the outside provider deems the athlete medically able to return to participation, it is the responsibility of the athletic trainer to further determine functional (or sportspecific) readiness to return to full participation. Athletic trainers should work cooperatively with the treating physicians and communicate frequently throughout the athlete's recovery.

Athletic trainers should recognize that physicians are the higher medical authority. ${ }^{26}$ The athletic trainer has an ethical obligation to maximize the well-being of the athlete and minimize the liability exposure of the school. Therefore, when the athletic trainer is unable to document evidence of functional levels sufficient to ensure the athlete's safety, the athletic trainer should express these concerns to both the treating and team physicians. Whether or not the treating physician agrees, authority for the final decision on the athlete's return to play should remain with the team physician. The team physician should be willing to 


Model
Athletic trainer employed by athletic
Most comment
Monodel historically
Team physician employed externally; serves
voluntarily or is contracted for service to
institution or school (athletics only or
institution as a whole), either through
retainer or fee for service
Athletic trainer typically splits responsibilities
between athletics and academics per
contract or employment agreement; or AT
may be employed by athletics and
compensated additionally or given release
time for academic service
Athletic trainer may perform administrative
oversight, including financial, logistic, and
operational aspects of sports medicine
program

Athletic trainer and team physician employed full time by athletic department

Usually found in larger institutions with greater financial resources, medical demands

Athletic trainer may provide administrative oversight, including financial, logistic, and operational aspects of sports medicine program

Athletic trainer employed by educational program

More common in secondary schools than collegiate settings

Team physician usually employed externally; serves voluntarily or is contracted for service to institution or school (athletics only or institution as a whole), either through retainer or fee for service; or team physician may be employed by educational program

Athletic trainer typically has primary responsibilities in academics as instructor or preceptor and defined role in athletics; split responsibilities may be part of regular contract or AT may be employed by academics and compensated additionally or given release time for athletic service

Athletic trainer or team physician (or both) employed by university health center or school health services

University health center provides all health care services to students, including athletes

Advantages

Disadvantages

Allows closer relationship between sports medicine and athletic department personnel

May enhance communication between medical staff and athletics

Allows closer relationship between sports medicine and athletic department personnel and between team physician and AT

May enhance communication between medical and athletic personnel

Clarifies team physician's responsibility

Reduces or minimizes conflict of interest in making medical decisions based solely upon athlete's medical needs

May provide AT professional advancement opportunities through academic promotions, longevity, enhanced credentials

Reduced conflict between classroomtaught clinical practices and those carried out in clinical setting, thereby improving consistency, instruction clarity for students

Increased expectation and monitoring of continuing education by educational department may encourage AT to stay current on evidence-based clinical practices, improving athletes' quality of care

Minimizes conflict of interest in making medical decisions based solely upon athlete's medical needs

Athletic trainer afforded all rights, privileges of medical provider
Potential conflict of interest if athletic personnel have significant control over athlete's medical care

Athletic trainer, team physician may be challenged by athletic personnel over inappropriate return to play, medical clearance, other medical decisions

Potential for role conflict if AT must sacrifice athlete medical care responsibilities for athletic department administrative, educational responsibilities

Potential conflict of interest if athletic personnel control athlete's medical care

Athletic trainer, team physician may be challenged by athletic personnel over inappropriate return to play, medical clearance, other medical decisions

Athletic personnel may perceive lack of commitment, increasing communication challenges between medical and athletic personnel

Athletic trainer may experience role conflict, sacrifice athlete's medical care for educational demands, responsibilities

Athletic department may perceive lack of commitment toward its personnel, increasing communication challenges with medical staff

Athletic department does not control athletes' health care or ATs' employment 
Advantages

Requires a well-thought-out communication
plan so that relationship is seamless and
timely information is provided to athletic
personnel

Medical care contracted with outside hospital or private group

Institution contracts to separate entity (usually hospital) for all medical services; contracts may be awarded based upon bids
Salaries typically comparable with those of other medical professionals

Administrative tasks usually assigned to staff members, freeing AT for clinical care and allowing better work-life balance

Staff with most expertise supervises medical services, billing, reimbursement, etc

Medical records, referrals, related services managed in 1 place without duplication, division of efforts

Comprehensive care for student-athlete facilitated as both participation-related and other health care delivered through health service

Significantly reduces athletic department's responsibility for and control over medical decisions and promotes unity among medical team

Can streamline continuity of care among medical providers
Disadvantages

Athletic department does not receive insurance reimbursements for sports medicine services

Health service staff must understand athletic program intricacies and demands; in-service education may be necessary

Student health services may not employ the most expert sports medicine specialists in area

Due to lack of medical expertise, institution may be challenged in evaluating competitive bids for best medical care provider versus best financial package

Some outside groups may lack appropriate personnel for every medical situation or specialty needs

Communication challenges between athletic and medical personnel may be greater

May be difficult to determine, reconcile appropriate needs for equipment, expendable supplies, staffing

Abbreviation: AT indicates athletic trainer.

overrule the treating physician if he or she agrees with the athletic trainer that it is necessary to restrict the athlete's participation status.

We recommend that

- Athletic trainers work under the direction of a team physician based on their state practice act and professional standards;

- Athletic trainers follow policies and procedures that are written in conjunction with the team physician and supported by the school administration;

- Athletic trainers communicate return-to-play concerns with the team physician, with whom the final authority rests;

- All athletes undergo a comprehensive preparticipation physical examination and no athlete be allowed to practice or compete until documentation of the examination is provided;

- All schools with athletic programs have emergency action plans that are written, posted, and practiced by all who have responsibility for the acute management of athletes' injuries and illnesses;

- All schools have an appointed or designated team physician; and

- All schools with athletic programs provide an adequate number of sports medicine providers, specifically and most appropriately athletic trainers, based on the number of athletic teams and athletes.

\section{Policy and Procedure Recommendations Regarding Administrative Authority for the Selection, Renewal, and Dismissal of Athletic Trainers in the College and University Settings}

The sports medicine staff should have final, unchallengeable authority for the health and welfare of the athletes. The athletic trainer should be appointed as a senior athletic administrator to provide for the health, safety, and welfare of all athletes and have input into administrative areas such as the budget, risk management, institutional liability, quality assurance, and athlete satisfaction. This organizational structure sends a clear message that the athletic director recognizes the value of and has esteem for athlete welfare. As a senior administrative appointment, the athletic director should not cede authority over sports medicine or sports medicine providers to a coach. The institution and all applicable employees should be aware of and adhere to all state regulations regarding the credentialing of all sports medicine providers.

The athletic trainer should be directed and supervised with regard to administrative tasks by the athletic director, with regard to medical competence by the team physician, and with regard to academic competence by the academic department chair or dean. A coach should never be the direct supervisor of an athletic trainer due to conflict-ofinterest concerns. All institutional employment protocols and procedures for selection, evaluation, renewal, and 


\begin{tabular}{|c|c|c|c|}
\hline & \multicolumn{3}{|c|}{ Personnel Involved } \\
\hline & Team Physician & Athletic Director & Principal \\
\hline \multirow{8}{*}{$\begin{array}{l}\text { Athletic trainer's } \\
\text { abilities assessed }\end{array}$} & Athletic training services ${ }^{a}$ & Education & Customer service \\
\hline & Education & Administrative duties & Communication skills \\
\hline & Customer service & Budgeting and finance ${ }^{b}$ & Attendance and punctuality \\
\hline & Communication skills & Equipment & Professional conduct \\
\hline & Quality of work & Parent or guardian and coaching education & \\
\hline & Professional conduct & Communication skills & \\
\hline & & Attendance and punctuality & \\
\hline & & Professional conduct & \\
\hline
\end{tabular}

a School nurse may be involved, depending on his or her level of interaction with the athletic program.

b School's business manager provides input.

dismissal should be followed. A clear, complete outline of the specific job expectations should be provided and understood before the employment agreement is finalized. When an athletic trainer has responsibilities to more than 1 department, a clear delineation of reporting lines, percentage of duty expectations, and performance-appraisal weighting should be established.

\section{Policy and Procedure Recommendations Regarding Administrative Authority for the Selection, Renewal, and Dismissal of Athletic Trainers in the Secondary School Setting}

Selection of an Athletic Trainer. If a head athletic trainer is on staff, this individual should have significant responsibility in the hiring process within the school's policies and procedures. This includes developing the position vacancy notice, reviewing applications, checking references, and confirming appropriate credentials and licenses of the candidates, as well as selecting the top applicants to begin the interview process. In the absence of a head athletic trainer, the athletic director and principal should be responsible for the hiring process, as well as the school's human resources department, if applicable.

All aspects of the athletic trainer position should be addressed in the interview. ${ }^{30}$ These include but are not limited to supervision, direction, evaluation, authority, budget, policies, protocols, and applicable district, state, and national laws, rules, analysis of liability, and malpractice coverage. It should be noted during the interview that unquestionable final authority for rendering medical decisions should rest with the team physician or his or her designee, who could be the athletic trainer.

Retention of an Athletic Trainer. Renewal of the athletic trainer's employment should be based on a comprehensive, fair, and equitable evaluation process involving all aspects of the job performance and duties. The evaluation process should be performed by the team physician, athletic director, and principal, each evaluating competence in their areas of responsibility as outlined in Table 2.

The team physician should evaluate athletic training services, and review of all nonmedical duties associated with functioning as an athletic trainer should be completed by the team physician, the athletic director, or principal or designee (or a combination of these). In some areas of the review, the athletic director and team physician may ask for a coach's input. The coach's comments should not be the only ones considered in the review process but can serve as a starting point for communication and dialogue. This way, personality conflicts and lack of understanding of the athletic trainer's responsibilities will not affect the review process. Just as the coach would not want the athletic trainer to evaluate his or her ability to coach or select starting line-ups or plays, the athletic trainer does not want the coach to assess how he or she evaluates, manages, and treats an athlete's knee injury. Situations in which the athletic director is also a coach may present a potential conflict of interest. In these cases, the performance review of the athletic trainer should be the responsibility of the team physician and a suitable alternate or designee (eg, assistant athletic director or principal).

Dismissal of an Athletic Trainer. The periodic performance-appraisal process holds employees accountable for competent performance in the following areas ${ }^{30}$ :

- Technical standards, derived from the job description;

- Behavioral standards, derived from the district handbook;

- Mandatory standards, applicable to all individuals;

- Goals and objectives, as mutually agreed upon at the beginning of service; and

- Competencies, developed in accordance with the individual's job and in compliance with governing agencies that set required standards.

In addition, the periodic performance-appraisal process should include the following ${ }^{30}$ :

- Needs assessment for future educational programming;

- Career development for future career aspirations;

- Physical-demands checklist to determine the physical requirements of each job;

- Educational record;

- Personal note section for documenting accomplishments; and

- Performance $\log$ for documenting corrective action in a specified time period.

An employee may appeal the review or dismissal decision to the appropriate school or medical administration within a specified time period if his or her overall performance appraisal score or any individual score is viewed as unsatisfactory. 


\section{Performance-Appraisal Tools for Athletic Trainers in the Secondary School and College and University Settings}

Performance Appraisal. Performance appraisals for athletic trainers in the athletic setting are an important assessment component for establishing an effective qualityimprovement program for the sports medicine team. The goal of this section is to provide a framework and resources that enable an administrator to effectively and efficiently evaluate the performance of sports medicine staff in a manner that enhances the selection, evaluation, retention, and support required to facilitate a successful sports medicine program that protects the athletes' well-being. These program-specific tools should be in addition to the institution's or school's normal human resources policies and practices.

The performance-appraisal tools should be based on established goals and job objectives for each athletic trainer and serve as a 2-way document providing an open, ongoing, active review process throughout the year. The appraisals should be goal oriented, focusing not just on past performance but also on future improvement and professional development. Performance appraisals should include 2 main areas: individual staff performance and athletic training services metrics.

Program Evaluation. Institutions and schools should have clearly written organizational charts that outline health care services reporting and supervision plans. All members of the sports medicine team should have clear, written job descriptions that serve as a platform for developing yearly goals and benchmarks and describing day-to-day job duties. These should be developed and reviewed at the beginning of the year so that staff can plan for and perform their jobs effectively. Supervisors should provide timely feedback and periodic review throughout the year, avoiding the 1-time, end-of-the-year assessment. This written and planned process allows for open and transparent communication between staff and supervisors. Written goals and benchmarks provide an objective basis for job success and movement toward promotion. Written job objectives can help demonstrate day-to-day workloads and priorities to athletic administrators and human resources departments.

Individual Staff Performance. Individual staff performance is best evaluated using tools available for both announced and unannounced evaluations. These tools should be designed for the specific setting (eg, athletic, clinic, health center, hospital, academic) so that athletic directors as well as health care administrators feel comfortable conducting the evaluation and interpreting the results.

The performance process should include not only tools but also a description of the process and the roles of all of the team members: team physician, athletic director, coaches, athletes, faculty, and peer athletic trainers.

Institutions and schools should distinguish between the roles of the athletic director and the team physician in the evaluation process. There should be options for allowing athletes the opportunity to provide feedback, such as through an athlete committee, a standard survey, a per-visit feedback form, or an exit interview. The goal is to allow coaches and athletes to provide valuable feedback in a manner that can lead to improvements in care and service.

Staff members should be encouraged to provide selfassessments of their performance toward accomplishing their set goals and job objectives. This helps with the 2-way communication model described above, as perceptions and expectations may differ between employees and supervisors.

A supervisor should be encouraged to have 1-on-1 meetings with each employee to discuss goals, accomplishments, continuing education, and areas for improvement. As noted throughout this section, the review process should be goal oriented and should take place throughout the year, rather than only at the end.

Teaching. An important component to some sports medicine programs is the education and clinical supervision of young professionals in accredited programs, in the secondary school setting, or teachingrelated classes. Staff workloads should account for teaching and clinical education responsibilities as well as medical care responsibilities. Many sports medicine staff members have a faculty teaching, adjunct instructor, or clinical instructor role that should be accounted for in the initial goal-setting stage and in individual job objectives at the beginning of the year and be tied directly to the instructor evaluations. These academic or clinical evaluations should be used as part of the staff member's overall performance appraisal and addressed within the promotion and remediation planning and workload modifications.

Promotion and Remediation Plans. Formal performance appraisals can be used in discussions on raises, promotions, and workload modifications. Performance appraisals should include a formal remediation plan with an established, individual timeline for each sports medicine team member to seek professional development opportunities and correct unsatisfactory actions.

Athletic Training Service Metrics. It is important to evaluate the overall sports medicine program in addition to individual staff performance. Outcomes from tracking specific metrics for the medical care of athletes provided in the sports medicine setting can supply data for administrators to assess whether the program works and can identify adjustments that may improve the service. The results are often used to support resource allocation and other policy decisions to improve service delivery and program effectiveness. Tracking metrics can be as simple as tallying the number of facility visits, injury evaluations, treatments performed, or insurance claims processed each year. An example of a more complex program-evaluation tool is the "Recommendations and Guidelines for Appropriate Medical Coverage for Intercollegiate Athletics." 31 An alternative service model tool that can help demonstrate the value and performance of a sports medicine program is the new College-University Value Model and forthcoming Secondary School Value Model. ${ }^{32}$

Self-assessment tools can be used to determine whether staff are following best practices and program policies and assess the adequacy of the health care facility. A walkthrough checklist for facilities and programs can be used to evaluate and serve as a guide. Athletic trainers transitioning into a new job or job setting can benefit from this type of checklist to search for gaps in the program that should be addressed. The "BOC Facility Principles" checklist ${ }^{33}$ or an emergency plan checklist for all athletic staff are 2 good 
examples of evaluation tools that measure program compliance and identify areas for improvement. The "Secondary School Student Athletes Bill of Rights" 34 also lists key components of a safe and effective athletic program.

Any gaps or expansions in service should follow a formal remediation plan for correcting the problems or realigning to the mission. These redirections in the program should involve a plan, timeline, and process for accomplishing the new goals.

\section{Repository for Forms}

In support of these aspects of sports medicine management, the NATA has created a repository of template forms (http://www.nata.org/sports-medicine-management), so that athletic trainers entering a new setting will not have to start from scratch. This repository is expected to grow and provide additional resources, which will promote consistency in evaluating athletic trainers across schools and institutions.

\section{DISCLAIMER}

The NATA and the Inter-Association Workgroup advise individuals, schools, athletic training facilities, and institutions to carefully and independently consider the recommendations. The information contained in the document is neither exhaustive nor exclusive to all circumstances or individuals. Variables such as institutional human resource guidelines, state or federal statutes, rules, or regulations, as well as regional environmental conditions, may impact the relevance and implementation of these recommendations. The NATA and the Inter-Association Workgroup advise their members and others to carefully and independently consider each of the recommendations (including the applicability of same to any particular circumstance or individual). The foregoing statement should not be relied upon as an independent basis for care but rather as a resource available to NATA members or others. Moreover, no opinion is expressed herein regarding the quality of care that adheres to or differs from any of NATA's other statements. The NATA and the InterAssociation Workgroup reserve the right to rescind or modify their statements at any time.

\section{REFERENCES}

1. Klafs CE, Arnheim DD. The Science of Sports Injury Prevention and Management: Modern Principles of Athletic Training. St. Louis, MO: Mosby; 1977.

2. Top End Sports: The sport and science resource: list of every sport. http://www.topendsports.com/sport/sports-all.htm. Accessed August 12, 2013.

3. National Federation of State High School Associations. 2011-12 high school athletics participation survey results. http://www.nfhs. org. Accessed August 12, 2013.

4. Statistic Brain. NCAA College Athletics Statistics. http://www. statisticbrain.com/ncaa-college-athletics-statistics. Accessed August 12, 2013.

5. National Federation of State High School Associations. The case for high school activities. https://www.nchsaa.org/intranet/ downloadManagerControl.php?mode=getFile\&elementID=7680\& type $=5$ \&atomID $=9981$. Accessed August 12, 2013.

6. Centers for Disease Control and Prevention (CDC). Sports-related injuries among high school athletes: United States, 2005-06 school year. MMWR Morb Mortal Wkly Rep. 2006;55(38):1037-1040.

7. LaBella C, Henke N, Collins C, Comstock RD. A comparative analysis of injury rates and patterns among girls' soccer and basketball players at schools with and without athletic trainers from 2006/07-2008/09. AAPexperieNCE Web site. https://aap.confex. com/aap/2012/webprogram/Paper15632.html. Accessed August 12, 2012.

8. American Medical Association. Policy H-470.995 Athletic (Sports) Medicine. https://ssl3.ama-assn.org/apps/ecomm/PolicyFinderForm.pl? site=www.ama-assn.org\&uri $=\% 2$ fresources $\% 2$ fdoc $\% 2$ fPolicyFinder $\%$ 2fpolicyfiles\%2fHnE\%2fH-470.995.HTM. Updated November 2012. Accessed August 12, 2012.

9. United States Department of Labor Bureau of Labor Statistics. Occupational Outlook Handbook. http://www.bls.gov/ooh/ healthcare/athletic-trainers.htm. Accessed August 12, 2013.

10. Bardes CL. Defining "patient-centered medicine." $N$ Engl J Med. 2012;366(9):782-783.

11. Creighton DW, Shrier I, Shultz R, Meeuwisse WH, Matheson GO. Return-to-play in sport: a decision-based model. Clin J Sport Med. 2010;20(5):379-385.

12. Wilkerson G. Patient-centered care and conflict interests in sports medicine-athletic training. Int $J$ Athl Ther Train. 2012;17(4):1-3.

13. Board of Certification, Inc. BOC Standards of Professional Practice. http://www.bocatc.org/images/stories/resources/boc_standards_of_ professional_practice_1212af.pdf. Implemented January 1, 2006. Accessed August 13, 2013.

14. National Athletic Trainers' Association. NATA Code of Ethics. http://www.nata.org/codeofethics. Implemented September 28, 2005. Accessed August 13, 2013.

15. Team physician consensus statement. Med Sci Sports Exerc. 2000; 32(4):877-878.

16. National Collegiate Athletic Association. 2012-13 NCAA Sports Medicine Handbook. Indianapolis, IN; 2012.

17. National Collegiate Athletic Association. 2012-13 NCAA Division I Manual. Indianapolis, IN; 2012.

18. Matheson GO, Shultz R, Bido J, Mitten MJ, Meeuwisse WH, Shrier I. Return-to-play decisions: are they the team physician's responsibility? Clin J Sport Med. 2011;21(1):25-30.

19. Furrow BR. The problem of the sports doctor: serving two (or is it three or four?) masters. Saint Louis Univ Law J. 2005;50(1):165-183.

20. Ross JR, Capozzi JD, Matava MJ. Discussing treatment options with a minor: the conflicts related to autonomy, beneficence, and paternalism. J Bone Joint Surg Am. 2012;94(1):e3(1-4).

21. The team physician and return-to-play issues: a consensus statement. Med Sci Sports Exerc. 2002;34(7):1212-1214.

22. Brukner P. Return to play: a personal perspective. Clin J Sport Med. 2005;15(6):459-460.

23. Best TM, Brolinson PG. Return to play: the sideline dilemma. Clin J Sport Med. 2005;15(6):403-404.

24. Mitten MJ, Mitten RJ. Legal considerations in treating the injured athlete. J Orthop Sports Phys Ther. 1995;21(1):38-43.

25. Almquist J, Valovich McLeod TC, Cavanna A, et al. Summary statement: appropriate care for the secondary school-aged athlete. $J$ Athl Train. 2008;43(4):416-427.

26. American Academy of Family Physicians, American Academy of Pediatrics, American College of Sports Medicine, American Medical Society for Sports Medicine, American Orthopaedic Society for Sports Medicine, American Osteopathic Academy of Sports Medicine. In: Bernhardt DT, Roberts WO. PPE: Pre-Participation Physical Evaluation. 4th ed. Elk Grove Village, IL: American Academy of Pediatrics; 2010. http://ebooks.aap.org/product/ ppe-preparticipation-physical-evaluation. Accessed August 13, 2013.

27. Casa DJ, Guskiewicz KM, Anderson SA, et al. National Athletic Trainers' Association position statement: preventing sudden death in sports. J Athl Train. 2012;47(1):96-118.

28. Drezner JA, Courson RW, Roberts WO, Moresso VN, Link MS, Maron BJ. Inter-association task force recommendations on emergency preparedness and management of sudden cardiac arrest in high school and college athletic programs: a consensus statement. $J$ Athl Train. 2007;42(1):143-158. 
29. Herring SA, Kibler W, Putukian M. Sideline preparedness for the team physician: a consensus statement. 2012 update. Med Sci Sports Exerc. 2012;44(12):2442-2445.

30. Ray R. Management Strategies in Athletic Training. 3rd ed. Champaign, IL: Human Kinetics; 2005:72-85, 95-110, 301-302.

31. National Athletic Trainers' Association. Recommendations and guidelines for appropriate medical coverage of intercollegiate athletics. http://www.nata.org/sites/default/files/AMCIARecsandGuides.pdf. Revised June 2007. Accessed August 13, 2013.
32. National Athletic Trainers' Association. College-university value model. http://www.nata.org/sites/default/files/College-Value-Model. pdf. Accessed August 13, 2013.

33. Board of Certification, Inc. BOC Facility Principles. http://www. bocatc.org/images/stories/resources/boc_facility_safety_1305af.pdf. Published April 2013. Accessed August 13, 2013.

34. Youth Sports Safety Alliance. Secondary school student athletes' bill of rights. http://www.youthsportssafetyalliance.org/sites/default/files/ docs/Athletes-Bill-of-Rights.pdf. Accessed August 13, 2013.

Address correspondence to Ron Courson, ATC, PT, NREMT-I, CSCS (Co-Chair), University of Georgia Athletic Association, PO Box 1472, Athens, GA 30603-1472, rcourson@sports.uga.edu, or Michael Goldenberg, MS, ATC (Co-Chair), The Lawrenceville School, 2500 Main Street, Lawrenceville, NJ08648,mgolden@lawrenceville.org.

\section{Appendix. 10 Principles to Guide Administration of Sports Medicine-Athletic Training Services ${ }^{a}$}

1. The physical and psychosocial welfare of the individual athlete must always be the highest priority of the athletic trainer and the team physician.

2. Any program that delivers athletic training services, including outreach services provided to secondary schools or other athletic organizations, must always have a designated medical director.

3. Sports medicine physicians and athletic trainers must always practice in a manner that integrates the best current research evidence within the preferences and values of each athlete.

4. The clinical responsibilities of an athletic trainer must always be performed in a manner that is consistent with the written or verbal instructions of a physician or standing orders and clinical management protocols that have been approved by a program's designated medical director.

5. Decisions that affect the current or future health status of an athlete who has an injury or illness must only be made by a properly credentialed health professional (eg, a physician or an athletic trainer who has a physician's authorization to make the decision).

6. In every case that a physician has granted an athletic trainer the discretion to make decisions relating to an individual athlete's injury management or sports participation status, all aspects of the care process and changes in the athlete's disposition must be thoroughly documented.

7. To minimize the potential for occurrence of a catastrophic event or development of a disabling condition, coaches must not be allowed to impose demands that are inconsistent with guidelines and recommendations established by sports medicine and athletic training professional organizations.

8. An inherent conflict of interest exists when an athletic trainer's role delineation and employment status are primarily determined by coaches or athletic program administrators, which should be avoided through a formal administrative role for a physician who provides medical direction.

9. An athletic trainer's professional qualifications and performance evaluations must not be primarily judged by administrative personnel who lack health care expertise, particularly in the context of hiring, promotion, and termination decisions.

10. Universities, colleges, and secondary schools should adopt an administrative structure for delivery of integrated sports medicine and athletic training services to minimize the potential for any conflicts of interest that could adversely affect the health and well-being of athletes.

a Used with permission from Human Kinetics. 